Research Article

\title{
Development of Ideal Hump Geometric Characteristics for Different Vehicle Types "Case Study" Urban Roads in Kafr El-Sheikh City (Egypt)
}

\author{
Sayed A. Shwaly $\mathbb{D}^{1},{ }^{1}$ Mohamed H. Zakaria ${ }^{D},{ }^{2}$ and Amal H. Al-Ayaat ${ }^{2}{ }^{2}$ \\ ${ }^{1}$ Public Works Dept., Faculty of Engineering, Mansora University, Egypt \\ ${ }^{2}$ Civil Engineering Dept., Faculty of Engineering, Kafr El-Sheikh University, Egypt
}

Correspondence should be addressed to Mohamed H. Zakaria; mohammed_hamed@eng.kfs.edu.eg

Received 28 September 2018; Accepted 2 December 2018; Published 19 December 2018

Academic Editor: Giulio Dondi

Copyright (c) 2018 Sayed A. Shwaly et al. This is an open access article distributed under the Creative Commons Attribution License, which permits unrestricted use, distribution, and reproduction in any medium, provided the original work is properly cited.

\begin{abstract}
In Egypt, speed humps are often thought as the best and cheapest tool to reduce vehicles speed and consequently decrease the number of potential accidents. The lack of standards in Egypt led to the installation of a number of speed humps with random dimensions and without good justification. They have become in many cases a source of disturbance and discomfort to drivers and passengers especially when they are poorly designed and located. So, standard design guidelines are disparately required. Three streets from the urban road network of Kafr El-Sheikh city were chosen to collect field data. A total of 51 speed humps were chosen for field data survey. Although there are many design shapes of speed humps, the study focused only on the sinusoidal type. As observed in the field survey, it was found that more than $74 \%$ of the observed road humps were of the sinusoidal type. The screening process resulted in only 24 sinusoidal shape speed humps from the 51 speed humps firstly chosen. For speed measurement, data were collected by installing a recording camera beside the road carriageway of each speed hump for an hour time interval. Spot speed for three types of vehicles was measured from the recorded videos for each site by using the logger program software. The operating speeds $\left(V_{85 \%}\right)$ at humps locations have been obtained for different vehicles. Regression analysis models were developed to represent the relationships between the operating speeds $\left(V_{85 \%}\right)$ at humps locations for motorcycles, passenger cars vehicles, and microbuses and three variables, hump length, hump height, and the spacing between successive speed humps. Generally, the results demonstrated that spot speed is significantly influenced by speed hump geometric dimension and the spacing between them. Finally, the developed regression lines can be used easily for setting the geometric dimensions for each proposed hump location.
\end{abstract}

\section{Introduction}

Traffic calming is defined by the Institute of Traffic Engineers (ITE) as "the combination of mainly physical measures to reduce the negative effects of motor vehicle use, alter driver behavior, and improve conditions for nonmotorized street users" $[1,2]$. Since speed humps are a very effective means of calming traffic, the main purpose of installation of speed humps is to reduce speed and volume of traffic to acceptable limits in order to enhance safety for pedestrians and motorists [3].

There are many traffic calming devices that could be noticed overall Egyptian roads. These are speed humps, speed bumps, speed tables, roundabouts, transverse rumble strips, optical speed bars, textured pavement, and cat-eye reflectors but the speed humps are considered the most used means of traffic calming in Egypt $[2,3]$.

In order to fight against speeding, the government and people opted for the construction of speed humps. As a result, the speed humps spread along most Egyptian roads, and they have become a source of disturbance to all road users. Also, they may result in considerable traffic jams; this is due to the random way in which humps are installed.

Speed humps can have different heights, base widths, and shapes. In fact, no particular design is suitable for all the 
types of vehicles using the road. Despite the widespread of speed humps in most Egyptian roads, standard design guidelines are not readily available. Consequently, there is an urgent need to investigate the effect of speed hump characteristics on vehicle speed, in order to determine the appropriate dimensions of different humps according to their purpose.

So, the main purpose of this paper is as follows:

(i) Conducting a field study to examine the impact of speed hump characteristics on hump-crossing speed for different vehicles types

(ii) Obtaining a statistical model to examine the impact of speed hump characteristics (length, height and distance between consecutive humps) on humpcrossing vehicle speed for different vehicles types

(iii) Developing the best models in graphical forms that can be a useful tool for highway and traffic practitioners to design hump geometric dimension for different speed control limits for different types of roads and vehicles

Finally, this paper presents the field data that have been collected and analyzed in order to evaluate the effect of speed hump characteristics on hump-crossing vehicle speed. Video recording data collection method was employed for an hour in each speed hump location in the chosen study area. The approaching vehicles spot speeds at humps' locations were then obtained from the video recordings for each site by using the logger program software. The data obtained for a number of urban roads in Kafr El-Sheikh city were then analyzed in order to develop the best model that can be generalized as a typical model in Egyptian cities.

\section{Background}

High traffic speed on local roadways led to an increase in unsafe roadway conditions for pedestrians and bicyclists. As a result, governments all over the world have focused on efforts on improving the safety of local communities to face these consequences [4]. Using measures to "calm" the traffic is one of the means to help governments do this effectively.

The most important objective of the traffic calming techniques is the reduction of speed o vehicles. This can be achieved using many different methods that involve modification of either the road layout or the drivers' behavior [5]. The traffic-calming techniques can be classified as given in [6]:

(1) Police enforcement

(2) Visual stimuli (traffic signs and signals)

(3) Tactile stimuli (devices that produce distinct noise and vibrations inside the passing vehicle)

Tactile stimuli include the vertical raising of the road pavement with the use of different devices such as "humps" and "bumps" which are currently installed in many countries. It should be mentioned that the most noticeable difference between speed hump and speed bump is that the length of the speed bump is shorter than that of speed hump for approximately the same height [7]. This short length of speed bump can seriously damage the passing vehicles as well as could lead to the loss of vehicle control if it is passed at unsafe high speed.

To give full description of a speed hump, several parameters are used. These parameters include geometric and layout design parameters. The geometric parameters include hump length, hump height, hump profile, and hump width as shown in Figure 1. The layout parameters include spacing between speed hump, construction materials, marking, and signage.

A speed hump is a raised area from the pavement, installed transversely to the traffic flow and having several design shapes such as sinusoidal, circular, parabolic, and flat-topped profile [3]. The speed humps are supposed to serve two main objectives, the first is to force the drivers to decrease their speeds to avoid the uncomfortable crossing on the hump and the second is to reduce the rate of accidents [2]. The speed humps can reduce the speed of vehicles gently to $15 \mathrm{~km} / \mathrm{h}$ to $30 \mathrm{~km} / \mathrm{h}$, and they may cover the entire width of the road or cover a part of it [7].

Length is the most important speed hump geometric design parameter where effective humps should be at least as long as a vehicle wheelbase to isolate the effects of entering and exiting the humps for these vehicles [8]. Speed hump heights can influence the magnitudes of vertical accelerations and the maximum levels of perceived discomfort [9].

There are many design shapes of speed humps. The oldest design shape is the Watts profile or circular speed hump. It is $s$ section of a 3.7-meter-long cylinder with a height of 75 to $100 \mathrm{~mm}$ extending over the whole width of the road [10]. Accordingly, another design developed in the United States is the Seminole profile or "flat top" hump. The design is characterized by the addition of a 3-meter flat section into the Watts profile hump with a total length of $6.7 \mathrm{~m}$ [10]. Figure 2 shows Watts and Seminole profile speed humps.

\subsection{The Impact of Speed Humps' Characteristics on Vehicles'} Speed. It is worth mentioning that very little work has been done to study the effect of speed humps' geometric characteristics on vehicles speed in Egypt since there is not nationally accepted standard or design guidelines for speed humps dimensions have been approved. On the contrary, past studies in a number of countries showed a decrease in the 85 th and 50 th percentile of speed at hump location [7, 11-17]. The operating speed (85th percentile speed) is defined as the speed at or below which $85 \%$ of all vehicles are spotted to travel under free-flowing conditions at a specific point [7].

There are also a number of studies that have examined the effect of changing the characteristics of the speed hump on vehicle speed [7, 17-19].

The effect of changing the hump height on speed reduction was studied by Antic et al. using different heights $(3 \mathrm{~cm}, 5 \mathrm{~cm}$, and $7 \mathrm{~cm})$ with a constant hump length [18]. A comparison and an analysis of these speed measurements 

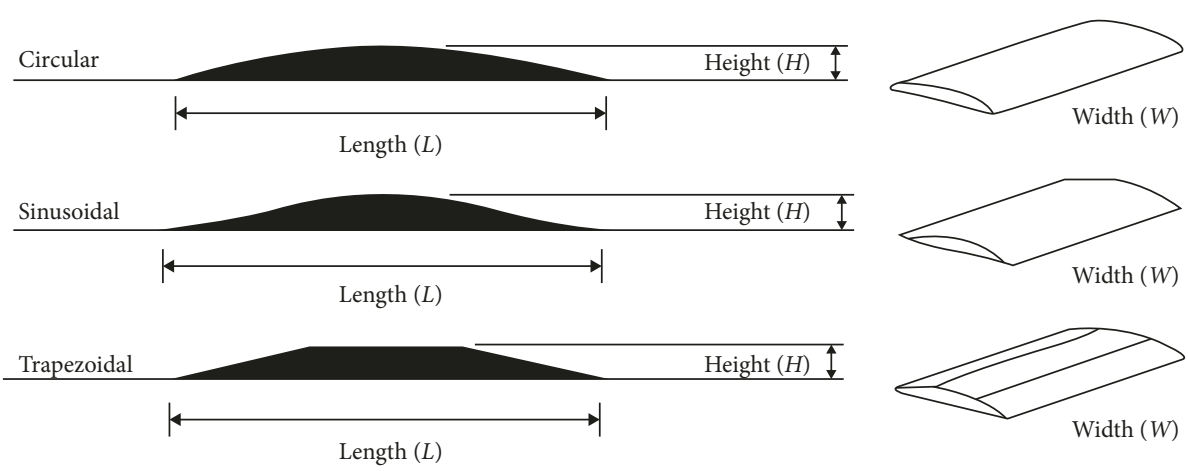

Figure 1: Geometric design parameters of speed hump [7].

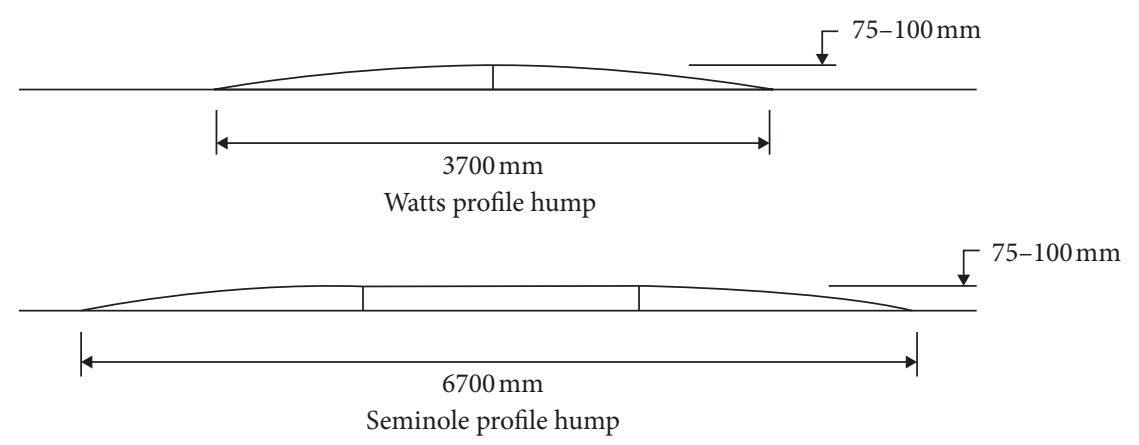

Figure 2: Watts and Seminole profile speed humps [10].

using ANOVA and post hoc are given in the study. Median speed $\left(V_{50 \mathrm{th}}\right)$ percentile and operating speed $\left(V_{85 \%}\right)$ percentile were compared to each other before and after speed bumps installation. Finally, as normally expected, it was found that the vehicle speeds reduced as hump height increased [18].

In the same context, a study was conducted by Yaacob and Hamsa in Taman Setapak, Kuala Lumpur, showed that the speed variations were larger in a hump of $60 \mathrm{~mm}$ height as compared to another hump of $80 \mathrm{~mm}$ height [19]. The gentler slope of the $60 \mathrm{~mm}$ hump resulted in more vehicles exceeding the speed limit $30 \mathrm{~m}$ before and after the road hump location [19].

Notably, there are not many studies that have been conducted to link the hump-crossing speed and different combinations of geometric design parameters of road humps, which include hump length, hump height, and the distance between consecutive humps.

According to the field study carried out by Sahoo in Bhubaneswar, India, on geometric characteristics of speed humps and hump-crossing speeds of two wheelers and passenger cars vehicles [17], the hump-crossing speed was predicted based on the area-to-width ratio of all 30 sites using different geometric designs of the speed humps, where $R^{2}$ equaled 0.56 for two-wheeled vehicles and 0.60 for passenger cars [17].

In Malaysia, field study was carried out by Zainuddin et al. to determine the relationship between the operating speed $\left(V_{85 \%}\right)$ reduction and the geometric design parameters of the hump [7]. A laser gun meter was used to determine the spot speeds at the specified locations of the speed humps. The results shown that a regression model could be developed, and this model can be used as the basis for designing a speed hump geometry (hump length and height) according to the operating speed $\left(V_{85 \%}\right)$ at speed hump location [7].

A study was conducted by Purnomo et al. in Surakarta, Indonesia, to analyze the correlation between speed bump dimensions and the observed speed of vehicles at a distance of 8 meters before the speed bumps [20]. The independent variables were the length and height of speed bumps and the dependent variable was spot speed [20]. The results showed that the height of speed bumps is the most influential factor to decrease speed in the area before the speed bumps [20]. On the other hand, Sundo and Diaz carried out a study to prove the relationship between the speed hump profile and the speeds at humps. There was a significant variation of the observed entry speeds [21]. Therefore, they pointed out that the height/length ratio was not a good explanatory variable to determine the entry speeds and that driver's behavior is also an important factor in determining vehicles speed [21].

In order to evaluate the speed profiles of individual vehicles on traffic-calmed streets in Christchurch, New Zealand, a study was conducted by Daniel et al. [22]. The study included speed data collection at 17 Residential Street in Christchurch. The Watts profile speed humps were $100 \mathrm{~mm}$ in height and ranged from $3.6 \mathrm{~m}$ to $3.8 \mathrm{~m}$ in length [22]. A ProLaser III light detection and ranging (LIDAR) meter was used to collect speed data. The results showed 
that the speed humps provide the lowest operating speed and are also the most effective mean in reducing the speed of the streets. The results also showed that at a spacing of 170 or more between speed humps, it is expected that the operating speed $\left(V_{85 \%}\right)$ will exceed $50 \mathrm{~km} / \mathrm{hr}$ [22]. The study recommended that the spacing between bumps should be $85 \mathrm{~m}$ or less if the desired speed is less than $40 \mathrm{~km} / \mathrm{hr}$. [22].

Despite the effectiveness of speed humps in increasing traffic safety, it may adversely affect the speed of emergency vehicles $[23,24]$. Some researchers have confirmed that the emergency response services are the toughest opponents to the installation of speed humps $[23,23]$. The delay time that occurs depends on the type of emergency vehicle and the desired operating speed. For instance, in the Montgomery County, the hump-crossing speeds for a tiller style ladder truck, a pumper fire engine, an ambulance, and an aerial tower truck were $9.7,14.5,13.9$, and $17.3 \mathrm{~km} / \mathrm{hr}$, respectively [24]. Consequently, the use of speed humps can cause a negative effect to emergency response times. If there no strict control on its installation process according to wellconsidered standards, other means should be considered for calming traffic in residential areas [2].

Based on the above, speed reduction is the main objective of using speed humps and thus increasing traffic safety. A review of the various studies indicates that the effectiveness of the speed hump depends on many factors, including geometric dimensions, speed hump shape, the spacing, the surrounding environment, and vehicle type. However, the information presented in previous studies is not always compatible. For example, many studies did not show the dimensions or number of speed humps, vehicle type, and the location of measurements. For this reason, it is difficult to compare previous studies due to the lack of consistent information.

\section{Data Collection Procedures}

The study was conducted in the city of Kafr El-Sheikh. It is the capital of Kafr El-Sheikh Governorate, Egypt. The city is located in the Nile Delta of lower Egypt and about $134 \mathrm{~km}$ north of Cairo. The population of the city, according to the last census in 2012 from the Central Agency for Public Mobilization and Statistics (CAPMAS), is 160,266 inhabitants. It is the fourth largest city in the Nile Delta area, and it hosts Kafr El-Sheikh University with its educational/ research institutions and educational hospitals, which are considered a trip destination for many students/employees/ patients. The road directorate of Kafr El-Sheikh city adopted some of the measures to reduce speeds in some areas inside and outside the city in order to maintain the safety of road users. One of these measures used is speed hump in order to reduce the speed and hence reduce the number and severity of potential accidents.

The data collection procedures involve field site survey. Data from the field site survey stage were screened to determine the suitable sites to conduct speed measurement as per the selection criteria given below. Then speed measurements were carried out using video shooting for an hour in the vicinity of each hump site. Spot speeds were obtained at each hump location using video recording technique. The logger program software was used for the analysis of the recorded data.

3.1. Urban Road Selection Criteria. Urban road selection criteria were set as a guide to select a number of urban roads in Kafr El-Sheikh city. Firstly, the selected residential area should have existing speed humps cited at the collector/ distributor or local streets. Secondly, the selected hump location should have sufficient vehicle volume to allow adequate data collection for speed so that a minimum of 50 samples can be obtained within an hour [25]. Thirdly, the selected urban areas chosen for data collection should be a combination of both old and new residential areas; hence, such mixed land uses include different environment and road user behavior which would be a typical situation in most Egyptian cities.

Therefore, three streets from the urban roads of Kafr ElSheikh city were chosen to collect field data. Table 1 shows geometric characteristics of the selected urban roads.

3.2. Field Survey. Two different types of data were measured and identified for all humps on the specific roads. The first type was the physical entity, which included the design shape, the geometric dimension of speed humps, the road width and the distance between successive speed humps, and the type of material the speed hump is made of. The second type was the nearby signs and devices, which included warning sign and road marking.

A total of 51 speed humps were found on the selected urban roads according to the criteria suggested earlier, and all the information were recorded based on the two characteristics mentioned above. Out of the 51 speed humps, there were 13 speed humps with a circular profile, while the remaining 38 humps with a sinusoidal profile. It should be mentioned that all observed speed humps are made of asphalt. Other speed humps made from other materials have been excluded this is because their number is a few.

3.3. Speed Humps Selection Criteria. In this stage, data from the field survey stage were screened to determine the appropriate locations for speed measurements. Although there are many design shapes of speed humps, the study was centered only around the sinusoidal type. As observed in the field survey, it was found that more than $74 \%$ of the observed road humps were of the sinusoidal type. It is worth mentioning that in this research, data were collected on permanent speed humps which are made of more rigid materials and are built as an integral part of the road. The common materials used in the construction of speed humps in Egypt are hot asphalt and cast concrete in place.

Speed humps selection criteria were set as a guide to select the suitable humps' locations for speed measurements. Firstly, these humps should have been established 
TABLE 1: Characteristics of the selected urban roads.

\begin{tabular}{|c|c|c|c|}
\hline Property & $\begin{array}{c}\text { Mubarak } \\
\text { street }\end{array}$ & $\begin{array}{c}\text { Abu Alaa Al } \\
\text { Ma'ari } \\
\text { street }\end{array}$ & $\begin{array}{c}\text { El-masn'a } \\
\text { street }\end{array}$ \\
\hline $\begin{array}{l}\text { Length of the } \\
\text { road }(\mathrm{m})\end{array}$ & 2400 & 1600 & 1150 \\
\hline $\begin{array}{l}\text { No. of lanes/ } \\
\text { approach }\end{array}$ & 2 & 2 & 2 \\
\hline Lane width (m) & 4.15 & 5 & 3.5 \\
\hline Median type & Raised & Raised & Raised \\
\hline Median width (m) & 4.2 & 4.2 & 4.8 \\
\hline $\begin{array}{l}\text { Speed limit } \\
(\mathrm{km} / \mathrm{hr})\end{array}$ & 55 & 55 & 50 \\
\hline
\end{tabular}

by the road directorate of Kafr El-Sheikh city. Secondly, the selected hump area should not have any other means for speed reduction except the presence of the hump. So, the hump location is rejected if it is near a signalized intersection or a sharp curve. Thirdly, humps that have severe defects in the pavement surface are excluded as in this case, the effect of the dimensions of the speed hump is not only the reason for speed reduction. Fourthly, the selected speed humps should be installed for more than 1 year to be sure of that the regular users of each hump were familiar with the hump dimension and able to cross the speed hump at their selected speeds without disturbing the occupants of the vehicle [26].

Based on the above, 24 speed humps out of the 38 speed humps that had a sinusoidal profile were selected. Figure 3 shows the urban roads and the locations of selected the speed humps.

3.4. Speed Measurements. There are several methods to obtain the spot speed of vehicles in a traffic stream and the most common methods are video analysis method, radar meter method, and stopwatch method. By using the stopwatch method, the spot speed can be easily measured using a small sample size observed during a relatively short distance and a short period of time. It is an inexpensive and quick method for conducting a speed study.

A radar meter is another common method for directly measuring the spot speed. The radar meter can be used in several modes, so it can be installed in a vehicle, installed on a tripod, or hand-held. It can be used for measuring speeds within a distance ranging from 200 feet up to 2 miles [27]. This device needs only one person to operate it and also needs a line of sight to accurate measurement for speeds. Two radar devices may be used if traffic condition is heavy. On the other hand, spot speed can be obtained from video analysis [28].

For spot speed measurements using a video recording method, it is required to set up a video recording camera on a tripod beside the hump location on the sidewalk. Two calibration marks or a reference distance can be selected on the screen for specific distance. After recording the video, it can be analyzed using some programs on the computer; one of these programs is called the logger program.
The logger program software is based on the fact that the speed of an object is a measure of how far it moves in a set time period. Therefore, the first step in calculating the speed of an object on a screen is to calculate the distance the object moved. Once this is determined, it is required to know what the frame rate of the video recording is. The frame rate, expressed as fps or frames per second, is the number of frames or images the camera can take per second [28]. The standard specification for the camera used in the speed measurements in this paper is $30 \mathrm{fps}$; this means that there is $1 / 30$ second between any two successive frames. Based on the above, the program can calculate the distance any object moves from one frame to the next and then calculate the spot speed of that object.

Due to the limited resources available in the university, the researcher has chosen the video camera method to obtain the vehicles' speed in vicinity of the hump location. In addition, the logger program software version 3.14.1 was utilized to calculate the vehicles' speeds in the vicinity of the hump location.

Data were collected by installing camera as shown in Figure 4 for only an hour at the free-flowing condition if traffic persists. Spot speed was calculated from the video recorded for each site by using the logger program software.

It is necessary to know the reference distance between two specific points, which is predetermined and marked on the pavement before starting the video recording as shown in Figure 4. This distance will be used later during the data analysis process in order to verify the speed measurements obtained from the logger software.

Only speeds of the passenger cars, microbuses, and motorcycles were collected for a minimum of an hour at every site. This is because the most prevailing vehicles' types found on the study area were passenger cars, microbuses, and motorcycles.

All vehicles' speeds were obtained near the humps' locations using the logger program software. Then using the Excel program, the operating speed at hump location has been determined. Table 2 shows the dimensions of the humps chosen for the study and the operational speeds of vehicles (i.e., passenger cars, microbuses, and motorcycles). It should be mentioned that motorcycle vehicle types include two and three wheels' vehicles such as motorcycles, tricycle, and tok-tok.

\subsection{Verification of Speed Given by Logger Program Software} Version 3.14.1. To check the speeds given by the program, the vehicle speedometer was compared at different distances from the hump with the speeds given by the software. This comparison process was done using a number of vehicles and with the help of the vehicle's driver; the speedometer reading is recorded at points previously identified on the road. At the same time, a video is recorded for the same vehicle, and the speed is obtained from the program at the specified points on the road, and thus one can compare the speed obtained from the program and the speedometer at the same points. The results were verified five times, and the mean values were taken as shown in Table 3. Figure 5 combines the program 


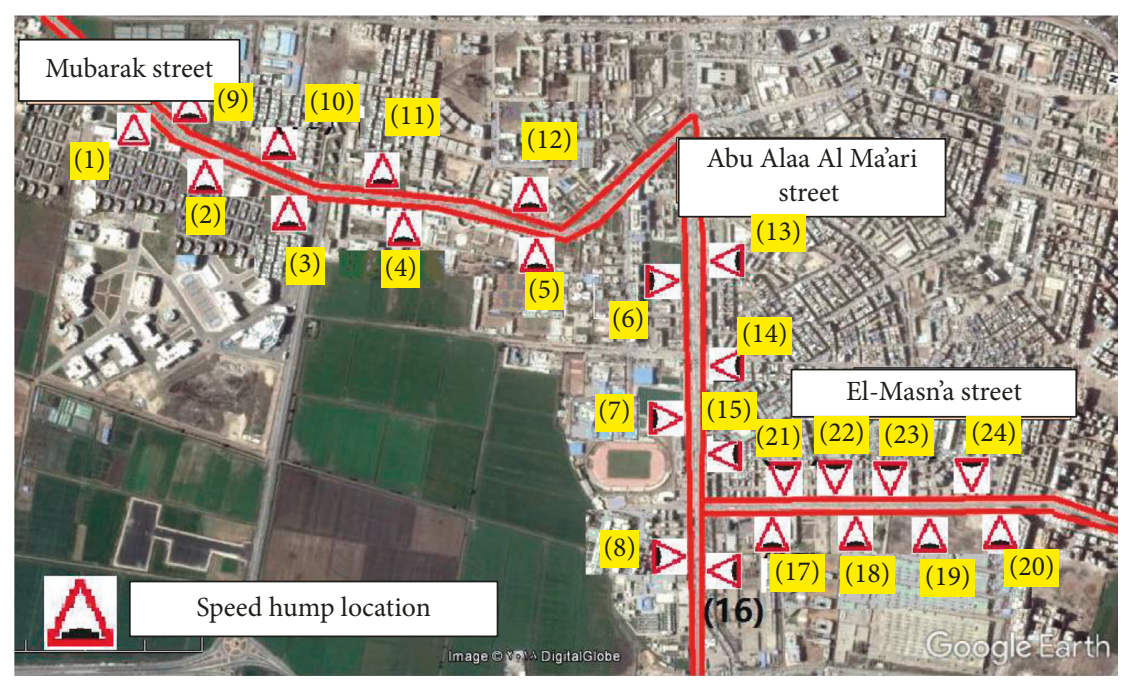

Figure 3: Urban roads and locations of the selected speed humps.

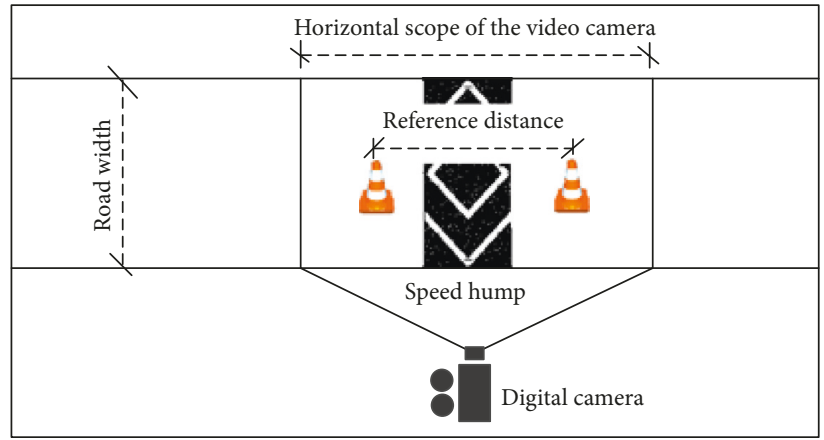

FIgURE 4: Installation of the digital camera at hump's location.

interface and spot speeds of a vehicle at different distances from a hump. Verification proved that the accuracy of the program results is greater than $90 \%$, and this is considered acceptable from the engineering viewpoint.

\section{Results and Analysis}

This section discusses the correlation and regression statistical analyses describing the relationships between the hump-crossing speed as a dependent variable and three variables, namely, hump length, hump height, and the spacing between speed humps as independent variables. The statistical package for the social sciences software (SPSS V22) program was used for conducting the statistical analysis of the obtained data.

4.1. Correlation Analysis. This section is devoted to describing the correlations between hump-crossing speeds and speed hump characteristics that mentioned above. This could help for better understanding of the association between hump-crossing speeds and variables representing speed hump characteristics. Table 4 shows the correlation coefficients between hump-crossing speeds and speed humps characteristics.
According to Table 4, the indicators of the correlation coefficients are as expected. For instance, the length of the speed hump has a positive correlation with hump-crossing speed. This means that the hump-crossing speed trends to increase as the length of the speed hump increases. While, the height of the speed hump showed a negative correlation with hump-crossing speed, meaning that the higher the height of speed hump, the lower the hump-crossing speed. Overall, the major observation is that the length and the spacing between speed humps have significant correlations with hump-crossing speed. On the contrary, it is clear that the height of speed hump has poor negative correlations with hump-crossing speed.

4.2. Regression Analysis. Regression analysis was used to represent the relationship between hump-crossing speed and three geometric variables (hump length, hump height, and the spacing between speed humps.). The regression analysis produced many mathematical models of the independent variables. The criteria used to assess the predictive accuracy of the models are as follows. Firstly, the higher the coefficient of determination $\left(R^{2}\right)$, the better the model is to represent the data. So, the R-squared coefficient must be as high as possible and significant at the $95 \%$ 
TABLE 2: The dimensions of the selected humps and operational speed.

\begin{tabular}{|c|c|c|c|c|c|c|c|}
\hline Hump no. & $\begin{array}{c}L \\
(\mathrm{~m}) \\
\end{array}$ & $\begin{array}{c}H \\
(\mathrm{~m}) \\
\end{array}$ & $\begin{array}{c}W \\
(\mathrm{~m})\end{array}$ & $\begin{array}{c}S \\
(\mathrm{~m})\end{array}$ & $\begin{array}{c}\text { Microbus } \\
V(85 \%)^{*} \\
(\mathrm{~km} / \mathrm{hr}) \\
\end{array}$ & $\begin{array}{c}\text { Passenger car } \\
V(85 \%)^{*} \\
(\mathrm{~km} / \mathrm{hr}) \\
\end{array}$ & $\begin{array}{c}\text { Motorcycle } \\
V(85 \%)^{*} \\
(\mathrm{~km} / \mathrm{hr}) \\
\end{array}$ \\
\hline 1 & 2.00 & 0.10 & 10.10 & 150.10 & 8.70 & 10.88 & 12.20 \\
\hline 2 & 3.25 & 0.08 & 14.00 & 310.00 & 19.58 & 24.84 & 28.44 \\
\hline 3 & 2.70 & 0.12 & 14.00 & 110.00 & 12.252 & 15.62 & 21.52 \\
\hline 4 & 2.70 & 0.10 & 12.00 & 180.50 & 13.32 & 15.48 & 21.21 \\
\hline 5 & 2.70 & 0.11 & 14.00 & 220.00 & 17.52 & 19.21 & 23.11 \\
\hline 6 & 4.90 & 0.10 & 15.00 & 360.10 & 26.64 & 33.12 & 38.25 \\
\hline 7 & 1.70 & 0.10 & 11.00 & 190.10 & 7.54 & 8.33 & 11.52 \\
\hline 8 & 1.70 & 0.11 & 13.00 & 220.20 & 8.25 & 9.21 & 13.52 \\
\hline 9 & 3.20 & 0.10 & 12.00 & 210.00 & 16.25 & 19.52 & 23.25 \\
\hline 10 & 2.00 & 0.12 & 10.00 & 150.00 & 7.50 & 8.85 & 10.89 \\
\hline 11 & 2.40 & 0.10 & 12.00 & 210.00 & 12.66 & 14.42 & 16.85 \\
\hline 12 & 2.20 & 0.08 & 10.00 & 340.00 & 8.80 & 13.32 & 17.88 \\
\hline 13 & 1.70 & 0.08 & 12.00 & 300.25 & 9.55 & 11.98 & 16.52 \\
\hline 14 & 1.60 & 0.08 & 10.00 & 85.00 & 7.02 & 10.44 & 15.48 \\
\hline 15 & 1.60 & 0.10 & 12.00 & 270.00 & 9.36 & 11.16 & 17.72 \\
\hline 16 & 1.50 & 0.12 & 9.00 & 180.00 & 4.95 & 5.70 & 8.62 \\
\hline 17 & 1.40 & 0.10 & 8.00 & 140.00 & 8.95 & 9.42 & 11.55 \\
\hline 18 & 2.40 & 0.12 & 9.00 & 100.00 & 10.21 & 11.10 & 13.21 \\
\hline 19 & 2.20 & 0.10 & 9.00 & 185.00 & 11.52 & 12.54 & 15.52 \\
\hline 20 & 0.90 & 0.10 & 7.00 & 200.00 & 4.75 & 5.91 & 6.80 \\
\hline 21 & 0.60 & 0.10 & 8.00 & 190.00 & 5.40 & 5.90 & 7.10 \\
\hline 22 & 0.50 & 0.10 & 8.00 & 250.30 & 6.66 & 7.56 & 13.14 \\
\hline 23 & 0.50 & 0.12 & 7.00 & 90.00 & 4.51 & 5.22 & 6.55 \\
\hline 24 & 0.50 & 0.08 & 8.00 & 200.00 & 5.76 & 6.69 & 10.44 \\
\hline
\end{tabular}

$V(85 \%)^{*}$ is the operational speed in kilometers per hour; $H$ is the height of speed hump, $L$ is the length of speed hump, $S$ is the spacing between the consecutive speed humps, and $W$ is the width of the road for each direction, all in meters for each approach.

TABLE 3: Verification of speed given by logger program software.

\begin{tabular}{lcccc}
\hline $\begin{array}{l}\text { Distance from hump (m) } \\
\begin{array}{l}\text { Speed from vehicle speedometer } \\
\text { (km/hr) }\end{array}\end{array}$ & 0.00 & 10.00 & 20.00 & 25.00 \\
$\begin{array}{l}\text { Speed from logger pro. software } \\
\text { (km/hr) }\end{array}$ & 17.90 & 33.48 & 41.23 & 43.21 \\
Percentage difference (error) & $5.75 \%$ & $7.50 \%$ & $4.10 \%$ & $4.00 \%$ \\
\hline
\end{tabular}

confidence level. Secondly, each of the independent variables should have regression coefficient that is significantly different from zero.

A number of models have been developed for the relationship between the speed on the hump and the hump characteristics. Table 5 shows the best-fit models for passenger cars, microbuses, and motorcycles according to previous criteria.

The best models are models A3 for microbuses, B3 for passenger cars, and C3 for motorcycles which can be written as the following equations:

$$
\begin{aligned}
V_{85 \%}(\text { microbuses }) R^{2}= & 0.880=0.973+4.491 L \\
& -14.88 H+0.010 S, \\
V_{85 \%}(\text { passenger cars }) R^{2}= & 0.915=4.85+5.638 L \\
& -59.0 H+0.012 S,
\end{aligned}
$$

$$
\begin{aligned}
V_{85 \%}(\text { motorcycles }) R^{2}= & 0.882=8.445+6.013 L \\
& -76.866 H+0.017 S
\end{aligned}
$$

where the following can be noted:

(i) $V_{85 \%}$ is the speed below which $85 \%$ of all the vehicles are driven in kilometers per hour, $L$ is the length of speed hump in meter, $H$ is the height of speed hump in meter, and $S$ is the spacing between successive speed humps

(ii) Equation (1) represents the predicted hump-crossing speed of passenger cars based on three independent variables, equation (2) represents the predicted hump-crossing speed of microbuses based on three independent variables, and equation (3) represents predicted hump-crossing speed of motorcycles based on three independent variables

The resulting coefficient of determination of the best model for microbuses $\left(R^{2}\right)$ is 0.880 , for passenger cars $\left(R^{2}\right)$ equal 0.915 and for motorcycles $\left(R^{2}\right)$ equal 0.882 . It is found to be significant at a $95 \%$ confidence level, as the significance of the F statistic is less than 0.001 . The hypothesis that each of the coefficients is equal to zero can be rejected at the $95 \%$ confidence. The $t$ value shows the relative importance of variables in the model, as the greater the $t$ value, the greater the contribution of the variables to the model. The coefficients of the independent variables are speed hump 


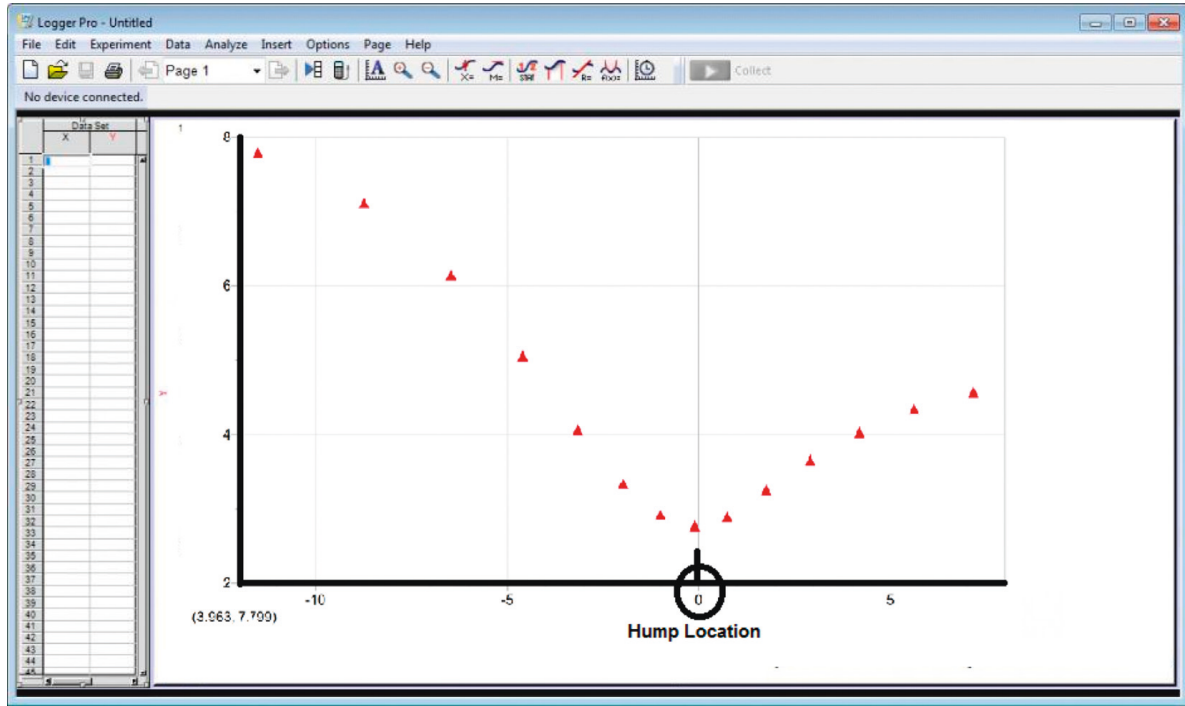

Figure 5: Program interface and the spot speed of the vehicle at different distances from a hump.

TABLE 4: Correlation coefficients between hump-crossing speeds and speed hump characteristics.

\begin{tabular}{lccc}
\hline Vehicle type & Height & Length & Spacing between humps \\
\hline Passenger cars & -0.208 & 0.931 & 0.535 \\
Microbuses & -0.240 & 0.924 & 0.496 \\
Motorcycles & -0.249 & 0.901 & 0.563 \\
\hline
\end{tabular}

TABLE 5: Results of the best achieved model for speed hump characteristics on hump-crossing speed.

\begin{tabular}{|c|c|c|c|c|c|c|c|c|}
\hline Model & & Variable & Constant & $L$ & $H$ & $S$ & $R^{2}$ & ANOVA $(F)$ \\
\hline \multirow{6}{*}{ Microbuses } & \multirow{2}{*}{ A1 } & Coefficient & -0.760 & 4.446 & - & 0.012 & \multirow{2}{*}{0.879} & \multirow{2}{*}{$76.032(0)$} \\
\hline & & $t(p$ value $)$ & -0.624 & 10.462 & - & 2.038 & & \\
\hline & \multirow{2}{*}{$\mathrm{A} 2$} & Coefficient & 5.027 & 4.857 & -26.653 & - & \multirow{2}{*}{0.879} & \multirow{2}{*}{$48.272(0)$} \\
\hline & & $t(p$ value $)$ & 1.558 & 11.954 & -0.804 & - & & \\
\hline & \multirow{2}{*}{ A3* } & Coefficient & 0.973 & 4.491 & -14.880 & 0.010 & \multirow{2}{*}{0.880} & \multirow{2}{*}{$48.720(0)$} \\
\hline & & $t(p$ value $)$ & 0.219 & 10.029 & -0.407 & 1.446 & & \\
\hline \multirow{6}{*}{ Passenger cars } & \multirow{2}{*}{ B1 } & Coefficient & -2.026 & 5.457 & - & 0.018 & \multirow{2}{*}{0.905} & \multirow{2}{*}{$99.898(0)$} \\
\hline & & $t(p$ value $)$ & -1.513 & 11.691 & - & 2.878 & & \\
\hline & \multirow{2}{*}{ B2 } & Coefficient & 10.085 & 5.978 & -93.256 & - & \multirow{2}{*}{0.904} & \multirow{2}{*}{$98.577(0)$} \\
\hline & & $t(p$ value $)$ & 2.909 & 13.773 & -2.816 & - & & \\
\hline & \multirow{2}{*}{ B3* } & Coefficient & 4.85 & 5.638 & -59.040 & 0.012 & \multirow{2}{*}{0.915} & \multirow{2}{*}{$71.826(0)$} \\
\hline & & $t(p$ value $)$ & 1.048 & 12.078 & -1.548 & 1.633 & & \\
\hline \multirow{6}{*}{ Motorcycles } & \multirow{2}{*}{$\mathrm{C} 1$} & Coefficient & -0.507 & 5.778 & - & 0.025 & \multirow{2}{*}{0.856} & \multirow{2}{*}{$69.499(0)$} \\
\hline & & $t(p$ value $)$ & -0.287 & 9.391 & - & 3.001 & & \\
\hline & \multirow{2}{*}{$\mathrm{C} 2$} & Coefficient & 15.74 & 6.511 & -121.051 & - & \multirow{2}{*}{0.865} & \multirow{2}{*}{$42.666(0)$} \\
\hline & & $t(p$ value $)$ & 3.320 & 10.909 & -2.486 & & & \\
\hline & \multirow{2}{*}{$\mathrm{C} 3^{*}$} & Coefficient & 8.445 & 6.013 & -76.866 & 0.017 & \multirow{2}{*}{0.882} & \multirow{2}{*}{$50.048(0)$} \\
\hline & & $t(p$ value $)$ & 1.383 & 9.760 & -1.527 & 1.746 & & \\
\hline
\end{tabular}

Note. " $t$ " means the $t$-test statistic; * the best model; $H$ is the height of speed hump in meter, $L$ is the length of speed hump in meter, and $\mathrm{S}$ is the spacing between two consecutive speed humps.

length, height, and spacing between humps. The positive sign of the independent variables which include speed hump length and spacing between humps means that as the speed hump length and spacing between humps increase, humpcrossing speed also increases, as expected. However, the negative sign of the independent variable speed hump height means that as speed hump height increase, hump-crossing speed will decrease.
Figures 6-8 show the observed values of hump-crossing speeds $\left(V_{85} \%\right)$ plotted against the predicted speeds. It is noticeable that the observed values are closely correlated with those expected. The figures emphasize the validity of the models previously described.

4.3. Results Discussion and Sensitivity Analysis. The best mathematical models described previously can be 


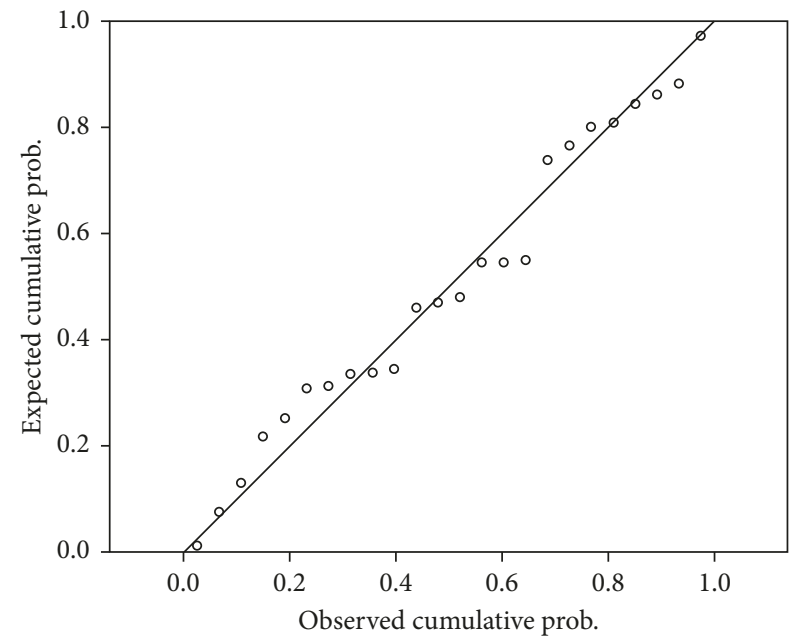

Figure 6: Predicted speed values against observed values for microbuses.

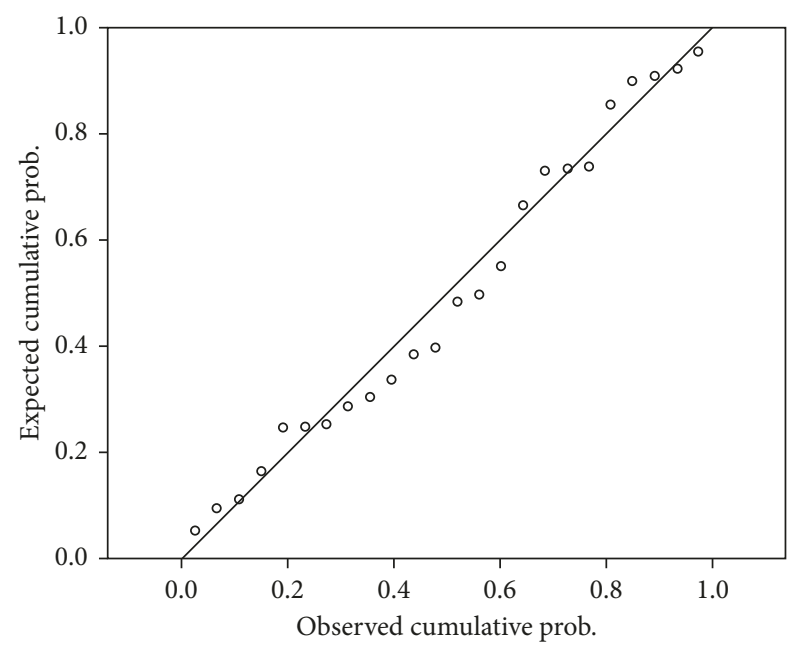

Figure 7: Predicted speed values against observed values for passenger cars.

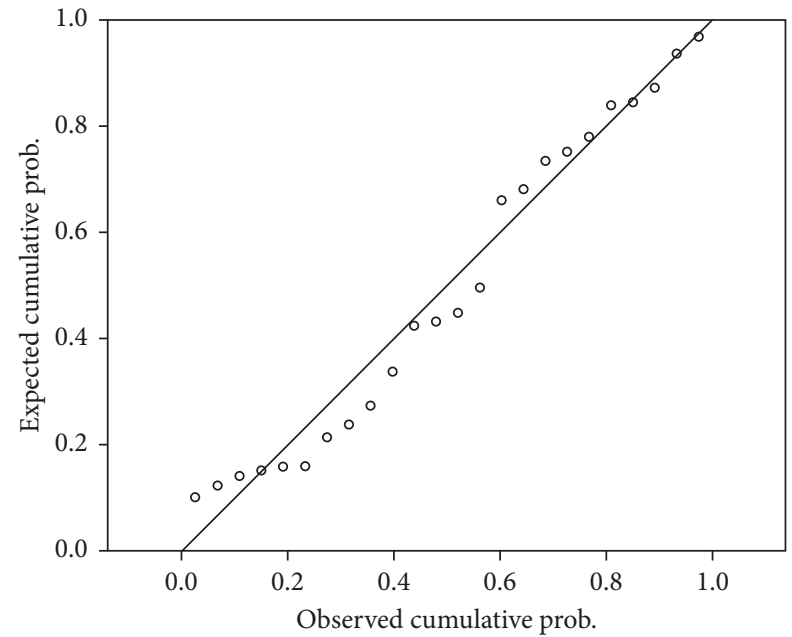

Figure 8: Predicted speed values against observed values for motorcycles. represented in graphical forms. These graphs can be a useful and fast tool for highway and traffic practitioners to design hump geometric dimension for different speed limits for different types of vehicles. Also, the potential operating speeds of different speed humps can be compared for different types of vehicles as well as the sensitivity analysis can be conducted.

By using the MATLAB program version 9.1, a program was created so that the equations obtained previously can be converted into monograms. Figures 9-11 present the bestdeveloped relationships. Depending on the traffic composition, the design vehicle can be selected and the appropriate monogram will be selected. Accordingly, hump geometric characteristics can be chosen based on predicted humpcrossing speed and vice versa.

\section{Conclusions and Recommendations}

The main objective of this study was to develop ideal hump geometric characteristics for different vehicles types crossing speeds. Three urban roads in Kafr El-Sheikh city (Egypt) have been chosen for data collection. Only 24 speed humps installed on these roads were selected for crossing speed measurements of different vehicles' types. The collected data of geometric characteristics and spot speeds of vehicles on these humps were analyzed from the recorded videos on the sites using the logger program software. The most important findings of this paper can be summarized as follows:

(i) Based on the field study on humps characteristics and hump-crossing speeds of passenger cars, microbuses, and motorcycles vehicles, the results have shown that statistically significant regression relationships could be predicted.

(ii) A strong correlation was found between the hump-crossing speed and speed hump characteristics. The height of speed hump showed a negative correlation with hump-crossing speed. On the other hand, a strong positive correlation was found between length and hump-crossing speed. In addition, a strong positive correlation between the distance between the successive humps and vehicles speed.

(iii) Regression analysis was used to produce the best relationship between each hump-crossing speed and speed hump characteristics (length, height, and spacing between successive speed humps). Three models were developed for each vehicle type mentioned earlier. The resulted models showed a significant prediction accuracy with $R^{2}$ of 0.915 for passenger cars, $R^{2}$ of 0.880 for microbuses vehicles, and $R^{2}$ of 0.882 for motorcycles.

(iv) The developed models are presented in graphical forms. These relationships can be a useful tool for the highway and traffic practitioners and field engineers to design hump elements for specific speed 


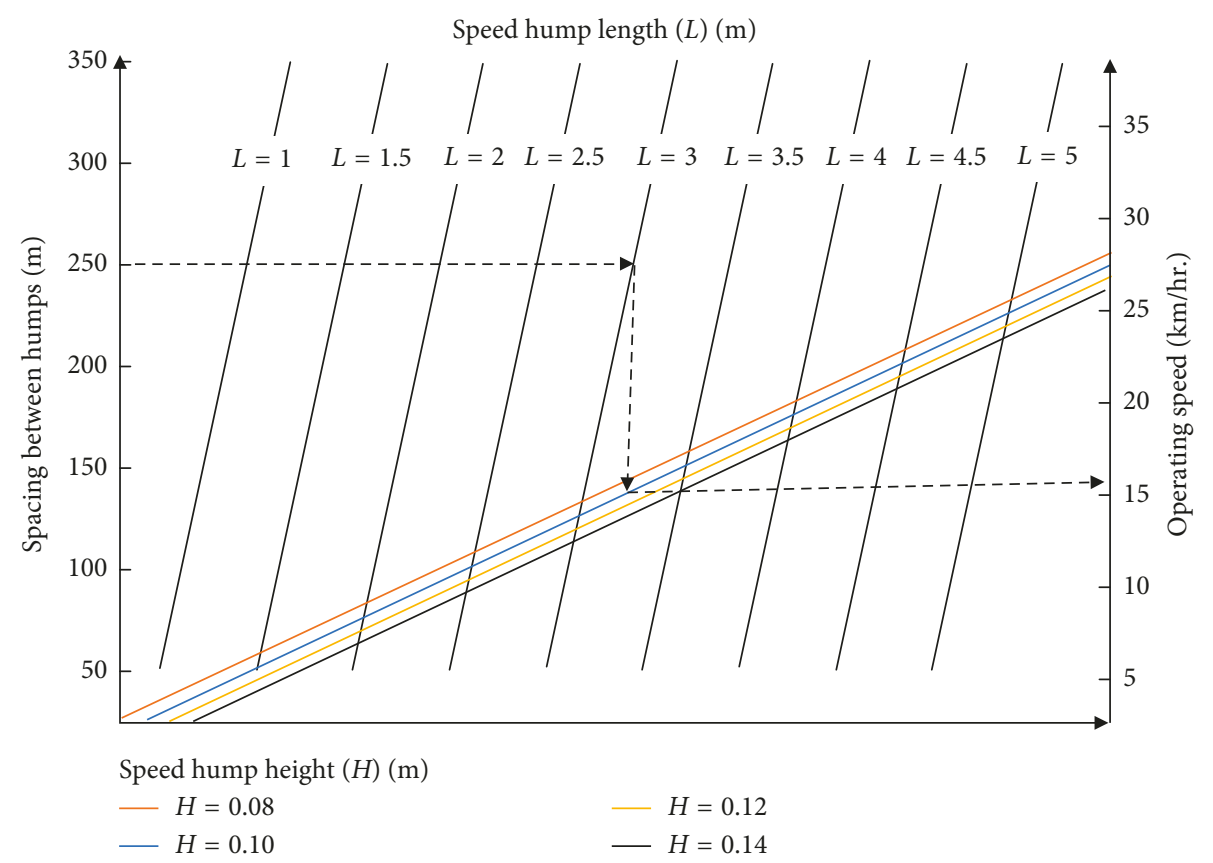

FIgURE 9: Predicted hump-crossing speed $\left(V_{85 \%}\right)$ based on hump characteristics for microbuses.

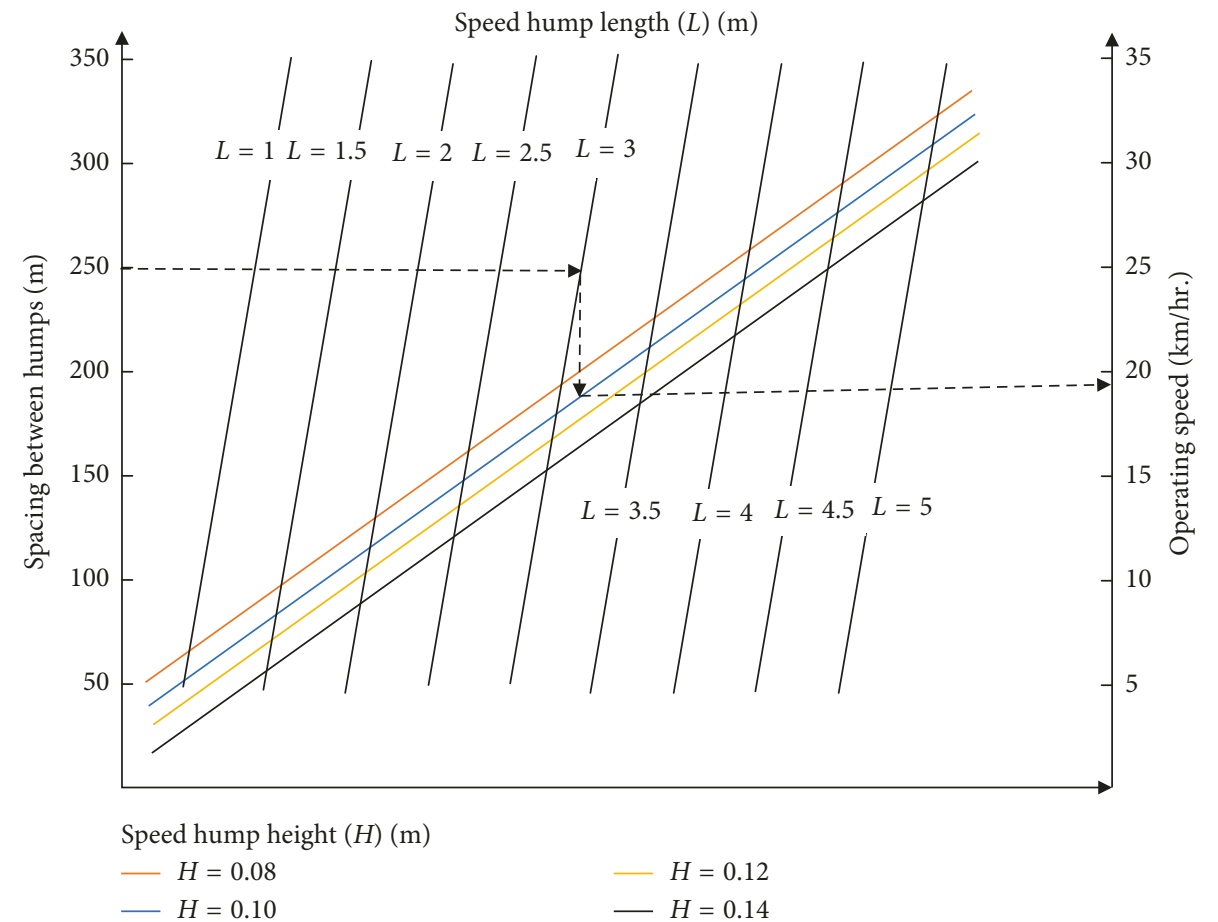

FIGURE 10: Predicted hump-crossing speed $\left(V_{85 \%}\right)$ based on hump characteristics for passenger cars.

limit or estimating hump-crossing speed based on speed hump characteristics.

(v) Based on the findings of this study, it is very necessary for the roads directorates to put generalized standard and specifications when speed humps are required. The specification should give geometric hump characteristics (length, height, shape, and spacing between humps) based on the desired speed reduction. Developed models in this study can be used to achieve this purpose.

(vi) The speed humps are supposed to serve two main objectives: the first is to regulate the traffic process and the second is to reduce the rate of accidents. Some other factors may need further studies such as 


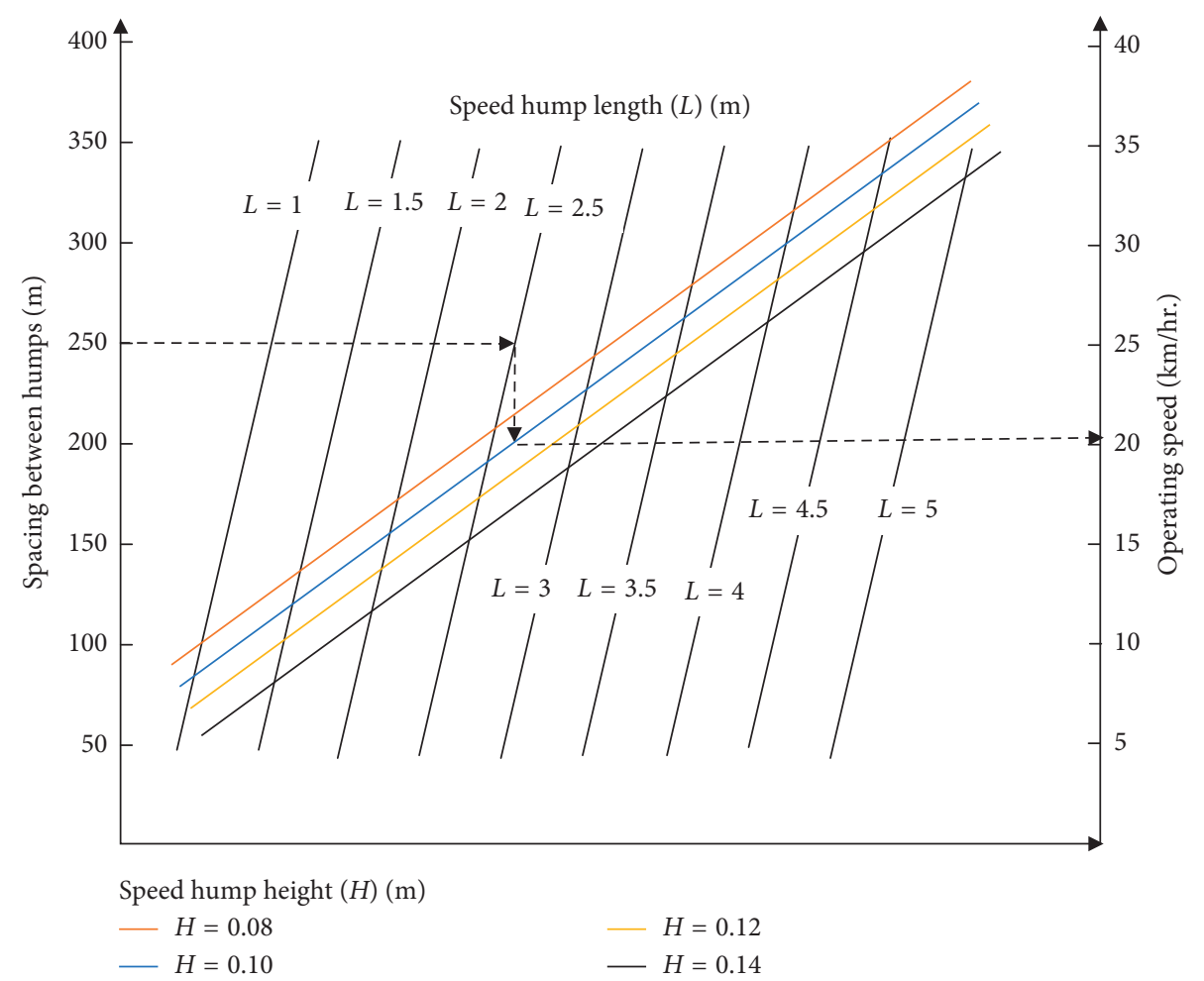

Figure 11: Predicted hump-crossing speed $\left(V_{85 \%}\right)$ based on hump characteristics for motorcycles.

the effect of humps on pavement conditions, the breakdown of vehicles, and the surrounding environment.

(vii) Most of the previous researchers have addressed the effects of speed humps on vehicles speed and accident rate based only on field data and simulations models. The results of field studies can be analyzed taking into account the public consultation and their opinion on the speed humps effectiveness since the public opinion survey may enhance the proposed speed humps geometric characteristics.

\section{Data Availability}

The data used to support the findings of this study are available from the corresponding author upon request.

\section{Conflicts of Interest}

The authors declare that they have no conflicts of interest.

\section{References}

[1] I. M. Lockwood, "ITE traffic calming definition," ITE Journal, vol. 67, no. 7, pp. 22-24, 1997.

[2] S. Shwaly, A. AL-Ayaat, and M. H. Zakaria, "Public evaluation of speed humps performance and effectiveness," Civil Engineering Journal, vol. 4, no. 6, p. 1206, 2018.

[3] T. A. Abdel-Wahed and I. H. Hashim, "Effect of speed hump characteristics on pavement condition," Journal of Traffic and
Transportation Engineering (English Edition), vol. 4, no. 1, pp. 103-110, 2017.

[4] J. H. Svara, T. C. Watt, and H. S. Jang, "How are US cities doing sustainability? Who is getting on the sustainability train and why?," Cityscape, vol. 15, no. 1, pp. 9-44, 2013.

[5] M. Pau, "Speed bumps may induce improper drivers' behavior: case study in Italy," Journal of Transportation Engineering, vol. 128, no. 5, pp. 472-478, 2002.

[6] M. A. Dixon and J. A. Jacko, "An investigation of tactile and visual stimuli in the roadway environment," Perceptual and Motor Skills, vol. 87, no. 2, pp. 387-394, 1998.

[7] N. I. Zainuddin, M. A. Adnan, and J. Md Diah, "Optimization of speed hump geometric design: case study on residential streets in Malaysia," Journal of Transportation Engineering, vol. 140, no. 3, article 05013002, 2014.

[8] J. R. Jarvis, "An investigation of road humps for use on bus routes: final report," No. ARR222, Australian Road Research Board, Melbourne, Australia, 1992, ISBN: 0-86910-544-2.

[9] E. Kassem and Y. Al-Nassar, "Dynamic considerations of speed control humps," Transportation Research Part B: Methodological, vol. 16, no. 4, pp. 291-302, 1982.

[10] P. A. Weber and J. P. Braaksma, "Towards a North American geometric design standard for speed humps," Institute of Transportation Engineers (ITE) Journal, vol. 70, no. 1, pp. 30-39, 2000.

[11] K. Broadbent and A. Salmon, "An experiment with road humps," Highways and Transportation, vol. 38, no. 11, pp. 5-8, 1991.

[12] U. Engel and L. K. Thomsen, "Safety effects of speed reducing measures in Danish residential areas," Accident Analysis and Prevention, vol. 24, no. 1, pp. 17-28, 1992.

[13] A. A. Vis, A. Dijkstra, and M. Slop, "Safety effects of $30 \mathrm{~km} / \mathrm{h}$ zones in The Netherlands," Accident Analysis and Prevention, vol. 24, no. 1, pp. 75-86, 1992. 
[14] D. C. Webster, "Traffic calming: public attitude studies: a literature review," TRL Report 311, Transport Research Laboratory, UK, 1998.

[15] D. C. Webster and R. E. Layfield, "Traffic calming-sinusoidal, "H" and "S" humps," TRL Report 377, Transport Research Laboratory, UK, 1998.

[16] M. Pau and S. Angius, "Do speed bumps really decrease traffic speed? An Italian experience," Accident Analysis and Prevention, vol. 33, no. 5, pp. 585-597, 2001.

[17] P. K. Sahoo, "Geometric design of speed control humps in Bhubaneswar City," International Journal of Advance Civil Engineering and Technology, vol. 1, no. 1, pp. 70-73, 2009.

[18] B. Antić, D. Pešić, M. Vujanić, and K. Lipovac, "The influence of speed bumps heights to the decrease of the vehicle speedbelgrade experience," Safety Science, vol. 57, pp. 303-312, 2013.

[19] N. A. Yaacob and A. A. K. Hamsa, "The effect of road hump in reducing speed of motorcars in a residential area in Kuala Lumpur," Journal of Design and Built Environment, vol. 13, pp. 1-13, 2013.

[20] R. D. Purnomo A, D. Handayani, and Syafi'i, "Correlation analysis between speed bump dimensions and motorcycle speed in residential areas," MATEC Web of Conferences, vol. 195, p. 04013, 2018.

[21] B. M. Sundo and C. E. D Diaz, "Effect of hump spacing on speed selection of isolated vehicles: the case of exclusive villages in Metro Manila," Proceedings of the Eastern Asia Society for Transportation Studies, vol. 3, no. 2, pp. 409-423, 2011.

[22] B. D. Daniel, A. Nicholson, and G. Koorey, "Analysing speed profiles for the estimation of speed on traffic-calmed streets," Road and Transport Research: A Journal of Australian and New Zealand Research and Practice, vol. 20, no. 4, p. 57, 2011.

[23] L. W. Bunte, "Traffic calming programs and emergency response: a competition of two public goods," Doctoral dissertation, University of Texas at Austin, Austin, TX, USA, 2000.

[24] S. Hallmark, K. Knapp, G. Thomas, and D. Smith, "Temporary speed hump impact evaluation," No. CTRE Project 00-73, 2002.

[25] R. Ewing, Traffic Calming State of the Practice Slide Seminar, Institute of Transportation Engineers, Federal Highway Administration, Washington, DC, USA, 1999.

[26] T. F. Fwa and C. Y. Liaw, "Rational approach for geometric design of speed-control road humps," Transportation Research Record, no. 1356, pp. 66-72, 1992.

[27] K. Parma, "Survey of speed zoning practices: an informational report," Institute of Transportation Engineers, Washington, DC, USA, 2001.

[28] L. Johnson and A. Nedzesky, "A comparative study of speed humps, speed slots and speed cushions," in Proceedings of ITE Annual Meeting, Lake Buena Vista, FL. USA, August 2004. 


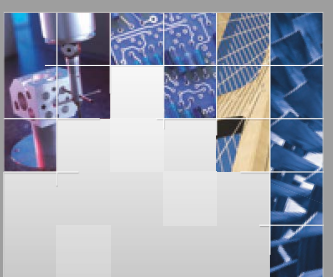

\section{Enfincering}
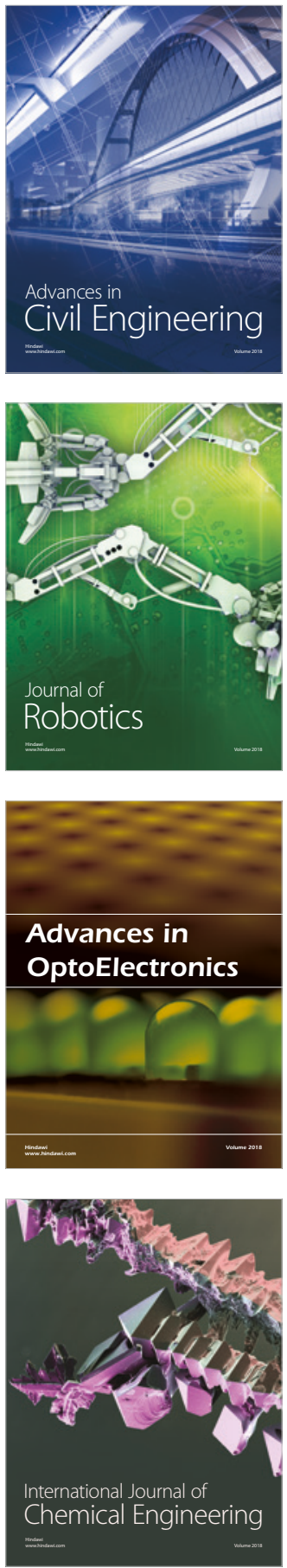

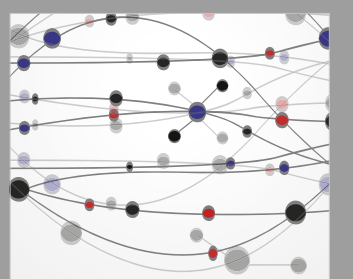

\section{Rotating \\ Machinery}

The Scientific World Journal

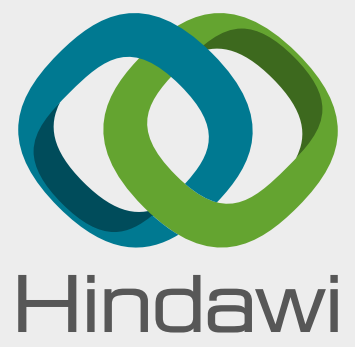

Submit your manuscripts at

www.hindawi.com
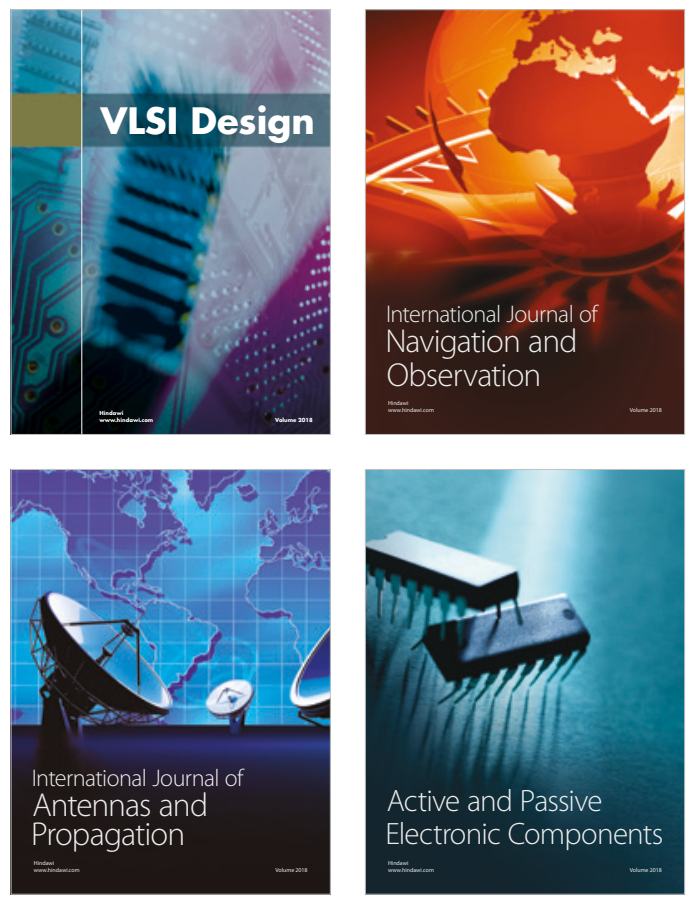
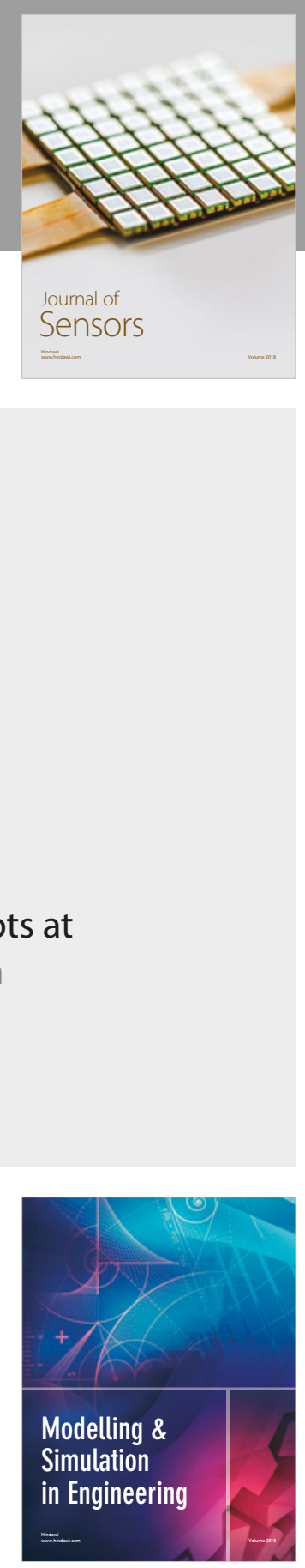

\section{Advances \\ Multimedia}
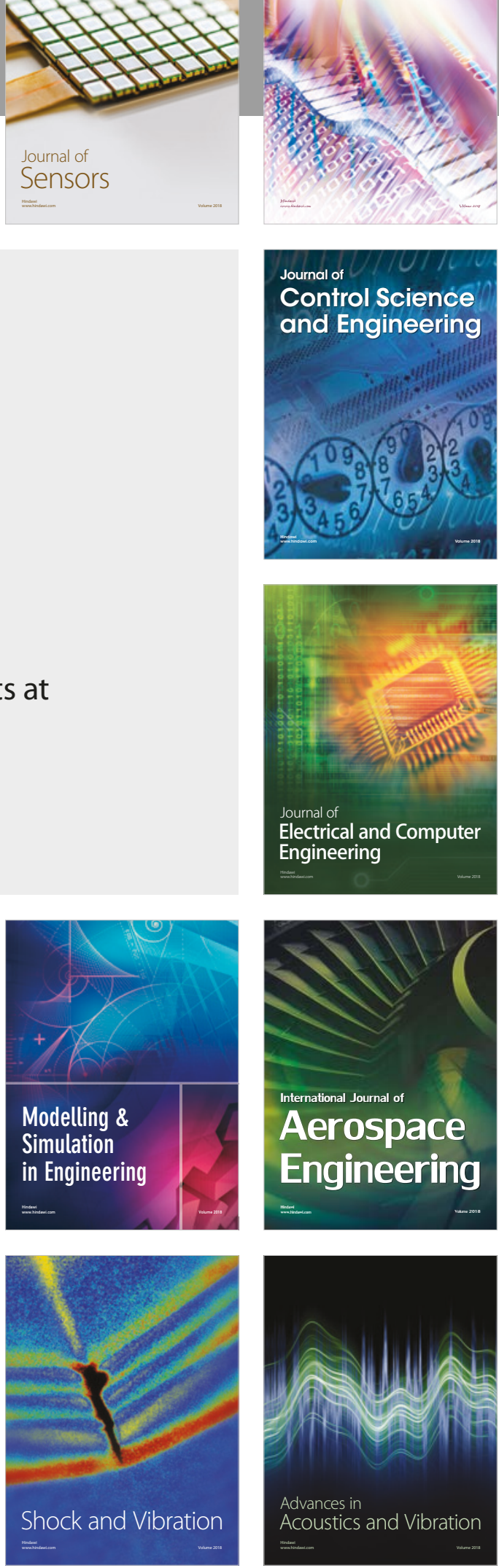